Review

\title{
Sustainable Electric Vehicle Transportation
}

\author{
Raymond Kene ${ }^{1, *}$, Thomas Olwal ${ }^{1}\left(\mathbb{D}\right.$ and Barend J. van Wyk ${ }^{2}$ \\ 1 Department of Electrical Engineering, Tshwane University of Technology, Pretoria 0183, South Africa; \\ OlwalTO@tut.ac.za \\ 2 Faculty of Engineering and the Built Environment, Tshwane University of Technology, Pretoria 0183, South Africa; \\ VanWykB@tut.ac.za \\ * Correspondence: keneRO@tut.ac.za
}

Citation: Kene, R.; Olwal, T.; van Wyk, B.J. Sustainable Electric Vehicle Transportation. Sustainability 2021, 13, 12379. https://10.3390/su132212379

Academic Editors: Mohammad Miralinaghi, Ramin Shabanpour, Xiaozheng (Sean) He and Samuel Labi

Received: 26 August 2021

Accepted: 30 October 2021

Published: 9 November 2021

Publisher's Note: MDPI stays neutral with regard to jurisdictional claims in published maps and institutional affiliations.

Copyright: (C) 2021 by the authors. Licensee MDPI, Basel, Switzerland. This article is an open access article distributed under the terms and conditions of the Creative Commons Attribution (CC BY) license (https:// creativecommons.org/licenses/by/ $4.0 /)$.

\begin{abstract}
The future direction of electric vehicle (EV) transportation in relation to the energy demand for charging EVs needs a more sustainable roadmap, compared to the current reliance on the centralised electricity grid system. It is common knowledge that the current state of electricity grids in the biggest economies of the world today suffer a perennial problem of power losses; and were not designed for the uptake and integration of the growing number of large-scale EV charging power demands from the grids. To promote sustainable EV transportation, this study aims to review the current state of research and development around this field. This study is significant to the effect that it accomplishes four major objectives. (1) First, the implication of large-scale EV integration to the electricity grid is assessed by looking at the impact on the distribution network. (2) Secondly, it provides energy management strategies for optimizing plug-in EVs load demand on the electricity distribution network. (3) It provides a clear direction and an overview on sustainable $\mathrm{EV}$ charging infrastructure, which is highlighted as one of the key factors that enables the promotion and sustainability of the EV market and transportation sector, re-engineered to support the United Nations Climate Change Agenda. Finally, a conclusion is made with some policy recommendations provided for the promotion of the electric vehicle market and widespread adoption in any economy of the world.
\end{abstract}

Keywords: sustainability; transportation; electric vehicles; grid integration; grid impact; renewable charging infrastructure; strategic policies

\section{Introduction}

At the time of writing this journal, countries around the world are preparing to attend the 26th Conference of the Parties (COP26) to the United Nations Climate Change Meeting in Glasgow. Some of the core issues to be discussed will centre around the protection of our environment, decarbonization efforts to achieve a net-zero future and a review of the 2015 Paris Agreement set to achieve the $1.5^{\circ} \mathrm{C}$ global average temperature.

This study provides a valuable contribution from the perspective of the transportation industry's adoption of electric vehicles and how the electrification of the transportation sector will further enhance global climate change. It is very well known that global climate deterioration is attributed to the burning and consumption of fossil fuels by the industrial and residential sectors across all economies of the world. The United States and China are currently the largest economies in the world that consume fossil fuels [1]. The primary consumer of fossil fuels, judging by energy consumption by industry average, is the transportation sector, which accounts for more than $91 \%$ of petroleum energy consumed [2]. The transition from internal combustion engine (ICE) vehicles to zero-emission electric vehicles has already begun, with most global economies setting 2050 as the target year for net-zero emissions in the transportation sector. The United States of America, Canada, China, Britain, and most parts of the European Union are set to strategically phase out and ban the manufacturing and sales of petrol and diesel-powered vehicles from 2030. Norway 
appears to be one country that is taking the lead in this transition by setting 2025 as the target year to phase out ICE vehicle sales and manufacturing. These efforts towards a green industrial evolution will further stem the tide of global environmental pollution and improve on the "Paris Agreement" of the 2015 conference of the parties (CoP) to the United Nations Framework Convention on Climate Change (UNFCCC). Key to this agreement, as seen in "Article 2(1)(a)(b) of the 2015 Paris Agreement" [3], was the commitment made by 195 countries to drive decarbonization efforts to the stage where the global average temperature is limited to $1.5^{\circ} \mathrm{C}$ and GHG emissions are lowered. Inarguably, large-scale electric vehicle adoption, batteries, and charging infrastructure powered by renewable energy sources (and not fossil fuel-powered plants) will accelerate the transition towards the green industrial evolution within the transportation sector.

According to a report from the Bloomberg New Energy Finance on Electric Vehicle Outlook 2021 Executive Summary [4], there are currently 12 million passenger EVs and commercial EVs are estimated to have reached 1 million, while the category of two- and three-wheeler EVs are estimated to be 260 million. The report [4] also gave a picture of global electric vehicles by segment and market, as indicated in Figure 1, in that by 2025, the estimated number of passenger EVs is predicted to surpass 54 million and commercial EVs and E-buses combined will be over 5 million, while electric two- and three-wheelers will surpass 300 million.
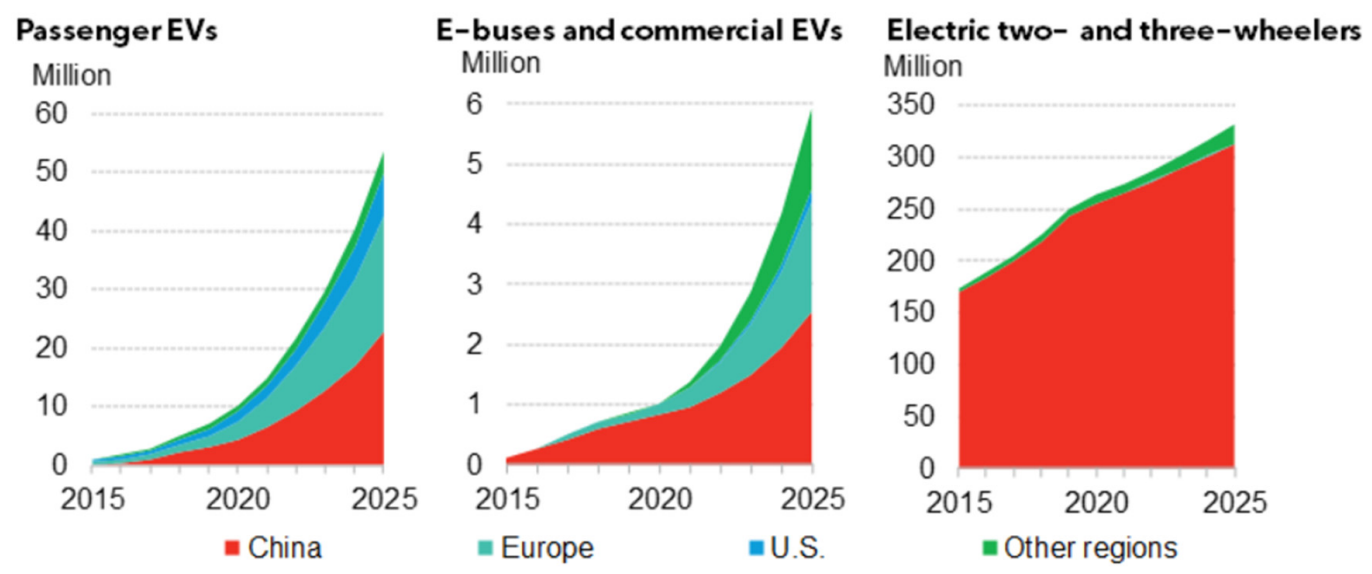

Source: BNEF. Note: Two-Wheelers includes mopeds, scooters and motorcycles, excludes e-bikes.

Figure 1. Global Electric Vehicle by Segment and Market. BloombergNEF: EV Outlook 2021 [4].

Engel et al. [5], under the auspices of the McKinsey Center for Future Mobility, conducted a similar study which suggested an exponential increase in large-scale electric vehicle adoption, reaching 120 million by 2030, in China, the European Union, and the United States alone. Figure 2 is a representation of McKinsey's base-case scenario for the exponential increase in EV adoption [5]. These figures suggest that the increasing number of EVs that will plug into the grid for battery charging will continue to grow. The consequential effect of this will cause the electricity grid-which was never designed to service large-scale EVs' load-to experience some level of instability, frequency deviation, and overloading of substations, amongst other uncertainties relating to the safety and stability of the electricity grid. Considering the three levels at which EV batteries can be charged, with level 1 capacity ranging from $1 \mathrm{~kW}$ but less than $10 \mathrm{~kW}$, level 2 charging above $10 \mathrm{~kW}$ but less than $40 \mathrm{~kW}$, and level 3 charging above $40 \mathrm{~kW}$, it is unlikely that the electricity distribution network will be able to sustain large-scale EV charging. To illustrate further using big and small economies, the most recent World Bank data on electricity power consumption per capita [6] shows that South Africa consumes about $4.198 \mathrm{kWh}$, while the United States consumes about $12.994 \mathrm{kWh}$. Assuming that an average of $2 \mathrm{kWh}$ of energy is consumed by an EV from the grid, the exponential increase of EVs over time suggests that the impact of large-scale EV to grid integration (EV2G) when added to the 
per capita consumption of electricity as indicated in [6] will adversely affect the energy system of any economy. This study therefore argues that this problem will further increase the global GHG emissions of $\mathrm{CO}_{2}$, making it difficult to achieve the $1.5^{\circ} \mathrm{C}$ limit of the Paris Agreement. In addressing this problem, this study aims to provide insight into some of the approaches that will enable sustainable EV transportation in addition to integrating renewable energy sources, such as solar power as an alternative option for charging EVs in the absence of grid-dependent fossil fuel energy.

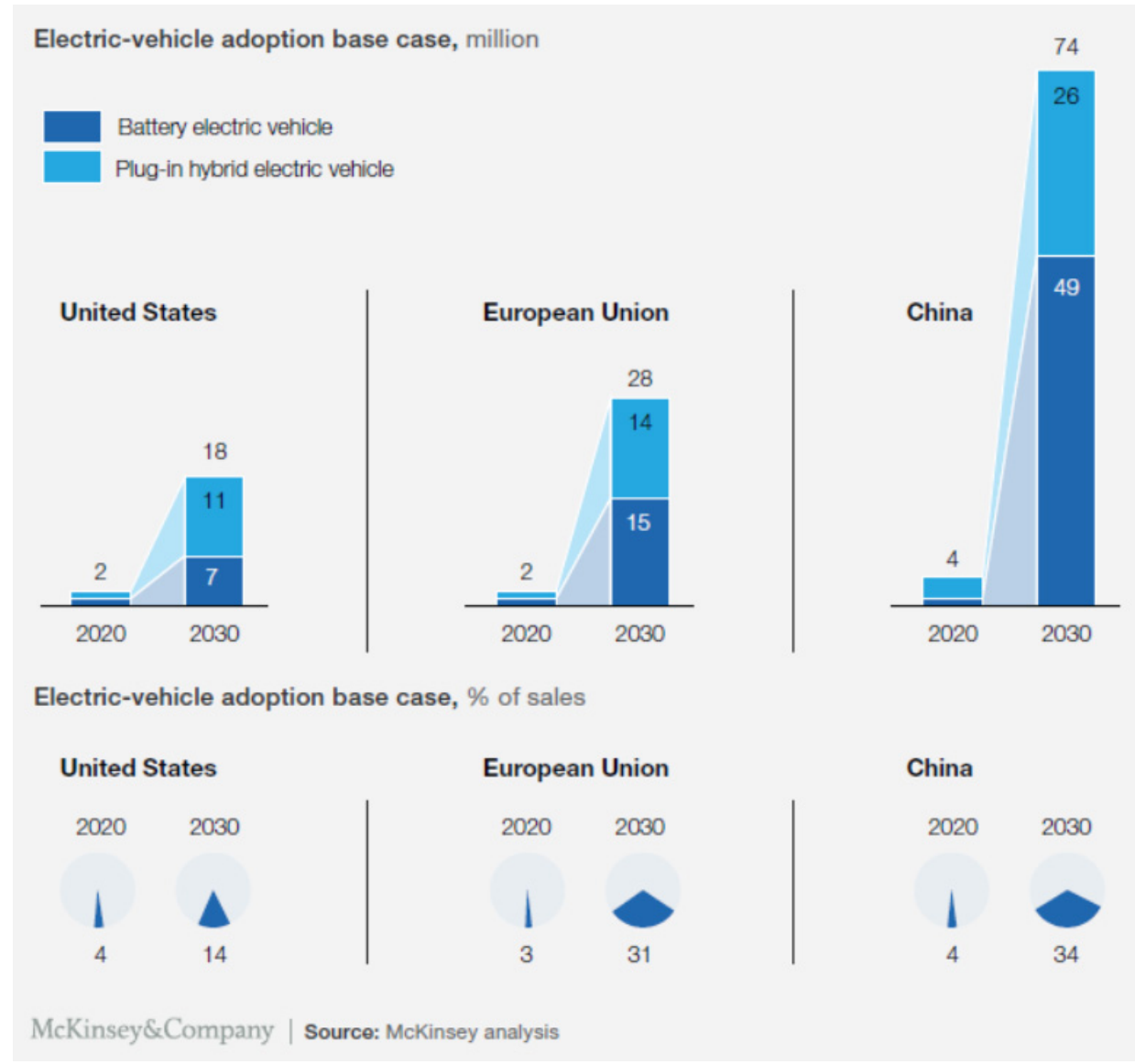

Figure 2. McKinsey's Base-Case Scenario for EV Adoption by 2030 for China, the EU, and the US.

\section{Large-Scale Electric Vehicle Impact: Implications for Grid Integration}

The integration of large-scale EVs into the electricity grid has continued to raise serious concerns about the security and stability of the grid. Gadh et al. [7] conducted a study that investigated the uncertainties associated with the impact of large-scale EVs on the distribution network and the problem of coordinating them. To solve this problem, the application of parametric diffusion kernel density estimation (DKDE) was employed to evaluate the energy required to charge large-scale EVs. In the case of the power flow problem for this study, an alternating direction method of multipliers was employed to address this issue. Singh et al. [8] investigated the impact analysis of plug-in electric vehicles (PEVs) on the distribution network using different charging models. The study highlighted that an increased number of PEV has a significant impact on the distribution network with obvious losses, peak loading, and transformer overload. The impact of EV energy demand on the distribution network of five countries from the European Union (the UK, Germany, Spain, Portugal, and Greece) was analyzed in a study conducted by Hatziargyriou et al. [9]. The analysis involved the use of dumb charging (EV charging on a residential grid system) as a method to establish that domestic energy consumption increases with EV integration. With this scenario, an increase in peak load energy demands on residential distribution networks 
was experienced in the summer, mostly in the afternoon, while in the winter season, the impact of EV energy demand from the grid shows a further increase in residential energy consumption during the evening due to peak load, which usually occurred in the evening.

An evaluation of the impact that different EV charging will have on Germany's national grid by 2030 was conducted by Hartmann et al. [10]. The investigation used three scenarios to gauge the future impact of the increasing large-scale integration of EVs on Germany's energy system. Using synthetic data with a minimum of one million EVs and up to a maximum of 42 million charging on the grid, the study established an increase in the peak demand of daily electricity. This first scenario demonstrated that the uncoordinated charging of EVs will certainly disrupt the stability of the distribution network. To cushion the effect of the first scenario, Hartmann et al. [10] considered the use of large-scale EV batteries to stabilize the electricity grid, which showed an improvement of $16 \%$ in the second scenario. This improvement from the second scenario was primarily because of the strategic and coordinated charging of EVs during off-peak periods and feeding the EVs' battery energy back to the grid (stabilization). The third scenario was purely for its economic benefit, whereby EVs were used for energy trading.

Weiller [11] conducted a research study on the impact of EVs' load demand on the US energy system. In analyzing the charging pattern and load profiles of EVs' hourly energy demand, the study used the US National Household Travel Survey of over 365,000 private vehicle trips. Using this dataset, a simulation model was conducted with input parameters such as battery charge depletion based on mileage, EV battery size, the efficiency of the charger, and the power level of the charger employed, amongst other parameters. Some of the results indicated that EV energy consumption can go up to $8.5 \mathrm{kWh} /$ day, which increases the electricity consumption per capita [6]. In other words, large-scale EVs charging at the same time will impose a significant increase on the peak demand of daily electricity consumption and constrain the stability of the power grid. Axsen et al. [12] conducted a study using three scenarios to investigate the impacts of plug-in hybrid electric vehicles (PHEVs) in California. In the first scenario, using the unconstrained method for charging EVs, this study established the potential impact of increased peak demand, which can significantly affect grid stability and may require that additional electricity be generated to meet the growing demand of uncontrolled large-scale EVs charging. The second scenario, which involved the use of workplace amenities to charge EVs, indicated an increase of $27 \%$ in electricity consumption, while the last scenario involved a control strategy of load shifting of EVs charging to off-peak periods, which showed a significant reduction of $25 \%$ in the overall electricity consumption profile.

Salah et al. [13], in a study conducted using the distribution substations in Switzerland's energy system, argued that an increasing number of large-scale EV penetration will have a significant impact on the national grid. In a quest to understand how EV charging will impact the energy system, real-time capacity datasets from SWISS high-voltage grid substations, EV datasets comprising of $30 \mathrm{kWh}$ battery capacity, EV power consumption estimated at $0.15 \mathrm{kWh} / \mathrm{km}$, and the maximum travel range of $200 \mathrm{~km}$ based on the battery capacity and estimated consumption were used for modelling and analysis. Using the current electricity tariff and at $16 \% \mathrm{EV}$ penetration, the findings showed a stable performance from the distribution substation, even though charging activities were uncoordinated. However, with an exponential increase of large-scale EVs' uncoordinated charging exceeding the $50 \%$ penetration level, the performance of the distribution substations is most likely to be significantly impacted with overloads. Some of the recommendations made by Salah et al. [13] include the introduction of adaptive and dynamic electricity tariff schemes that encourages load shifting of EV charging to off-peak periods.

Foley et al. [14] studied the impact of 213,561 EVs on the Republic of Ireland and Northern Ireland single electricity market (SEM) using a model based on PLEXOS. In analyzing the potential impact, two scenarios that involved charging EVs during off-peak and peak periods were employed. The overall result indicated that off-peak charging has a minimal impact on the stability and safety of the electricity network. Furthermore, a 
reduction in carbon emissions of $\mathrm{CO}_{2}$ for both the off-peak and peak charging was indicated as 147 and $210 \mathrm{kt} \mathrm{CO}_{2}$, respectively. Fernandes et al. [15] investigated the impact of EV load demand on Spain's energy system, whilst considering its economic benefits and that of renewable energy sources' (RES) integration into the grid systems. Analysis of the operational cost and energy consumption profile on the energy system was done with and without EV integration to the grid. Results from this study showed that the cost of generating electricity with RES for charging EVs with average penetration levels is quite minimal. On the other hand, an increase in EV penetration levels imposes additional costs on the generation capacity. The study, however, noted that RES integration with EV2G integration will provide valuable ancillary services and a more sustainable energy system with reduced GHG emissions. Supplementary literature studies on the aggregated impact of large-scale EV charging on the distribution network can be seen in [16-18]. An entire literature survey on EVs' impact on distribution systems and the significance of carrying out safety assessments to ameliorate this impact can be read in [19]. The impacts of the coordinated and uncoordinated charging of EVs on the Western Australia distribution network based on the time of use and voltage unbalance factor, amongst other parameters, can be read in [20]. In trying to understand the impact of the uncoordinated charging of PEVs on the distribution network, an assessment to determine the actual performance of distribution networks as against the ideal performance was conducted in [21]. In concluding this section, an overview that summarizes the grid impact of EVs from the perspective of fast charging stations integrated into distribution networks can be read in [22]. It highlighted and reviewed power quality issues associated with EV fast-charging under high power mode and provides ways of improving this process to ensure grid safety and stability.

\section{Energy Management Strategies to Optimize PEV Load Demand on the Electricity Grid}

The impact of the electrification of vehicles has been established to be a threat to the security and stability of the electricity grid, as outlined above in Section 2. In this section, the focus on the context around the energy management strategy evaluation of EVs and minimizing the impact of EVs on the distribution network, including methodologies and tools used for optimization, is provided.

\subsection{Electric Vehicle Classification}

EVs are generally classified into the following distinct powertrains, namely battery electric vehicle (BEV), hybrid electric vehicle (HEV), plug-in hybrid electric vehicle (PHEV), and fuel cell electric vehicle (FCEV). Within the PHEV category, as depicted in Figure 3, there are two subcategories, namely (1) the series PHEV, which is otherwise popularly known as the extended-range electric vehicle (EREV), and (2) the parallel PHEV.

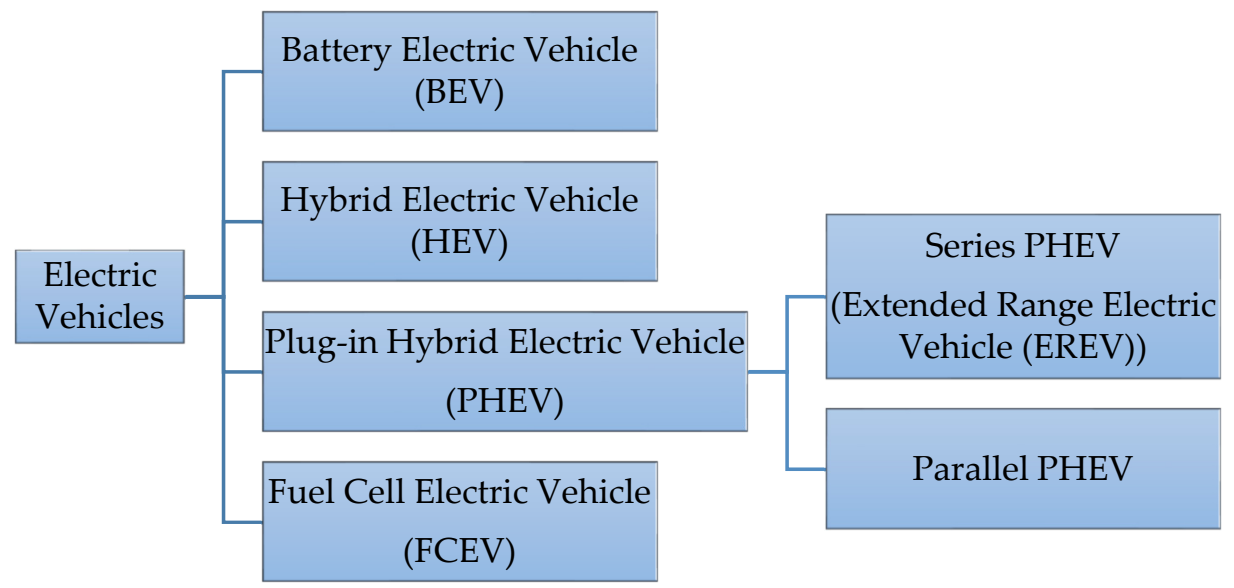

Figure 3. General Classification of Electric Vehicles. 


\subsubsection{Battery Electric Vehicle (BEV)}

The battery electric vehicle, otherwise known as purely EV or fully EV, has no internal combustion engine, hence its purely $100 \%$ electric driven powertrain with a very large battery power pack. With an intelligent energy management system (IEMS), the battery DC power is converted to AC power supplied to the electric motor which converts the electrical energy to mechanical energy required to drive the wheels. During the vehicle braking process (regenerative braking), the motor acts as an electrical generator (an alternator), which converts the mechanical energy (through a process known as kinetic energy recovery) from the brakes to the electrical energy required to charge the battery. Additional information can be seen in the Alternative Fuels Data Center of Energy Efficiency and Renewable Energy in the U.S. Department of Energy [23].

\subsubsection{Hybrid Electric Vehicle (HEV)}

Hybrid electric vehicles were not designed to charge from the grid. Instead, its configuration is such that includes a conventional ICE (using gasoline or diesel), which is smaller and more efficient with regular fuel tanks, battery power packs, and electric motors. The ICE is used to power the electric motor and charge the battery and the regenerative braking system is also employed to recover kinetic energy from the brakes for charging the battery and to power the electric motor [23].

\subsubsection{Plug-In Hybrid Electric Vehicle (PHEV)}

Plug-in hybrid electric vehicles, as the name suggests, combine the characteristics of the HEV and, in addition, were designed for grid integration. It has the conventional ICE, an electric motor, and a larger battery power pack than the HEV. The electric motor can be independently powered by either the ICE or the battery or a combination of the two. There are three modes available to charge the battery, namely using the ICE, regenerative braking, or through electrical outlets integrated into the electricity grid. Typically, the PHEV operates only in two modes, starting with the all-electric mode (also known as charge-depleting mode (CD mode)), which uses the battery and the electric motor to supply the power needed for all operations. The IEMS of the PHEV helps with energy management, monitoring, and control in this mode, in the sense that in the all-electric mode drive, the IEMS monitors the battery state of charge (SoC) and determines when to switch to the hybrid mode (the second mode of operation), where the ICE is now employed to drive the EV. In the second mode of operation, the IEMS switches the battery system to a mode known as the charge-sustaining (CS) mode. To maintain the required battery SoC in the CS mode, the IEMS uses the kinetic energy recovered from the regenerative braking process, and through the help of the electric motor which acts as an electrical generator (an alternator), energy is restored to the battery to sustain the required $\mathrm{SoC}$ [23].

\subsubsection{Fuel Cell Electric Vehicle (FCEV)}

Fuel cell electric vehicles have some similarities to the above-mentioned EVs, including an electric motor and a large battery power pack, except for the fact that FCEV generates electricity using hydrogen gas and atmospheric oxygen with the help of an onboard fuel cell stack. The electricity generated from the fuel cell stack and the battery power pack is used to drive an electric motor that propels the wheels [23].

\subsection{Energy Management of PEV Load Demand on the Distribution Network}

In order to evaluate the future uncertainties that are likely to affect the energy system in Colombia from large-scale grid integration of EV by 2030, Betancur et al. [24] developed a method to simulate the large-scale charging scenario of PEV using the Monte Carlo method. The model included parameters relating to the PEV daily mileage, charging behaviour that includes the battery $\mathrm{SoC}$, and PEV energy consumption, amongst other parameters. The outcome of the investigation indicated an upsurge of $20 \%$ and $40 \%$ in transformer and power lines overload arising from PEV charging power demand. 
Forecasting the charging demand of PEVs is one way to reduce the grid impact of largescale PEVs. This method was demonstrated by Jahangir et al. [25] by using an Artificial neural network (ANN) to estimate the impact of PEVs on the electricity distribution network. This investigation involved the use of Recurrent ANN based on the feedforward method and the Lavenberg Marquardt (LM) method of training data to forecast the travel behaviour and charging pattern of the PEVs. The result of the ANN simulation was compared with a benchmark simulation done with the Monte Carlo method. The result indicated that significant energy consumption costs can be reduced by an aggregator on a yearly basis.

An approach for the load management of PEVs integrated into the grid has been applied by Topic et al. [26]. Specifically, the authors [26] developed two models for PEV energy demand, using a deep neural network (DNN) to model the energy demand of PEVs. The first model predicts battery SoC and the associated fuel consumption during the PEV's driving cycle. The second model predicts the travel range limit associated with driving PEVs in all-electric mode (also known as charge-depleting mode (CD mode)). The neural network model showed better results in minimizing the charging energy costs of large-scale PEVs when compared with the traditional response surface approach.

Considering energy-efficient routing for EVs, De Cauwer et al. [27] conducted a study that predicted the energy consumption pattern of EVs using real-world driving datasets. A multiple linear regression (MLR) model was used to estimate the energy consumption of EVs, considering internal parameters like speed and acceleration and temperature as an external parameter, while the neural network was used to predict unknown parameters. According to [27], results from the models show a mean absolute error of $12 \%$ to $14 \%$ derived from the predicted energy consumption of the EVs.

Nageshrao et al. [28] conducted a study that employed optimal charging strategies to illustrate how the EV load demand can be managed to reduce the energy cost of electricity consumption from the grid. The result showed a 54\% improvement in cost optimization using coordinated charging strategies, as opposed to when an uncoordinated charging scenario was employed. Another approach employed by [28] to minimize the charging cost of EV operation involves using a neural network to predict the energy demand of EVs based on battery SoC and temperature. In order to be able to schedule EV charging and discharging operations, Morsalin et al. [29] used a neural network to make this intelligent decision. The approach involved the use of a smart metering device to obtain a dataset on household power consumption profiles and EV energy demand patterns. The neural network involved a feed-forward approach and a sigmoid function to train datasets that include parameters of battery SoC, EV trip time, and energy consumption. Using a nonlinear autoregressive with an external input (NARX) neural network, Jiménez-Bermejo et al. [30] were able to predict the EV battery SoC. The input parameters used to train the neural network were voltage and current, while the battery SoC represented the output of the network.

Using a nonlinear model predictive control (MPC) Pereira et al. [31] developed an energy management system (EMS) for FCEV and modelled the proton exchange membrane of the fuel cell using a recurrent neural network (RNN). Results indicated that the RNN which was trained with the Bayesian regularization algorithm in MATLAB shows accurate results of the FC voltage prediction, while the MPC model was able to minimize hydrogen consumption.

Park et al. [32] developed a controller using MPC to manage HEV energy while using ANN to predict future duty cycles instead of assumed duty cycles. The results indicated that the ANN predictions show a good fit for actual duty cycles and contribute to improving the HEV fuel economy. In a study conducted by Zhang et al. [33] which looks at the power management of PHEV, the use of MPC strategy was applied to control the output power between available battery power packs and ultracapacitors. In this case, the control strategy was optimized using a dynamic programming algorithm. This method was evaluated using three different driving cycles to validate the results, which indicated an improved fuel economy for the PHEVs. 
One of the major objectives of using IEMS in HEV operations is to maintain accurate SoC for the battery. This can be seen in the study conducted by Xiang et al. [34], which used a cascaded control concept that included three approaches, namely the use of a radial basis function ANN to predict vehicle velocity, the application of nonlinear MPC in a master controller that helps to maintain battery SoC and minimize the consumption of fuel, and the use of a slave controller based on a proportional integral derivative (PID) for engine and motor control. Further studies on MPC with comprehensive reviews on power management strategies for HEV considering prediction accuracy, design parameters, solvers, and other factors affecting MPC performance can be read from the study conducted by Huang et al. [35].

Considering the variables of fuel rate, battery SoC, and driveline power demand, Chen et al. [36] conducted a study that used a genetic algorithm (GA) to optimize the threshold of a power-split PHEV when the engine is switched on, while quadratic programming (QP) was applied for the estimate of the PHEV battery current. The result indicated that the energy management strategy was able to minimize PHEV fuel consumption. In order to reduce the peak power that will arise from the point of common coupling due to large-scale EV grid integration, Kucevic et al. [37] employed the use of linear optimization and time series modelling for the coordination of multiple battery energy storage systems. This model was evaluated on a distribution grid in order to assess the effective control and coordination of the BESS charging and discharging functions. The results indicated that an estimated $44.9 \%$ maximum peak load reduction can be achieved.

In a study conducted by Khaki et al. [38], where EV charging scheduling was formulated as an exchange problem, a novel hierarchical distributed electric vehicle charging schedule (HDEVCS) composed of a trilayer multiagent framework was developed to solve the exchange problem using the alternating direction method of multipliers (ADMM) as a solver. The results indicated that EV charging cost and the peak load demand were reduced significantly. In an effort to minimize EV charging costs and guarantee that EVs are fully charged, and giving the stochastic nature associated with EV arriving and living charging stations and the fluctuating electricity price, Li et al. [39] conducted a study to address this problem by formulating the charging and discharging schedule as a constrained Markov Decision Process (MDP) and applying a solver called safe deep reinforcement learning. The simulation for this experiment used the deep neural network to learn the datasets of EV constrained charging and discharging schedules.

\subsection{Tools for Modeling Electric Vehicle Load Demand Impact on the Distribution Network}

Literature studies, as seen in Section 3.2, have been able to describe some of the available approaches on the energy management of PEV load demand, which includes EV load demand forecast and the prediction of the battery SoC amongst many alternatives. This subsection presents some of the tools and approaches for modelling EV energy consumption and its impact on the electricity grid.

Using the load curves generated from EV charging profiles to measure the impacts of EV charging activities on Croatia's energy system, Novosel et al. [40] made attempts to model EV energy consumption based on the hourly distribution of energy supplied. To achieve this objective, the use of MATSim as an agent-based modelling tool was employed to determine the hourly distribution of energy demand by EVs, whereas, the impact assessment of the EV load demand on Croatia's energy system was done using the reference model created in EnergyPLAN for modelling.

Using deep reinforcement learning (DRL), Hu et al. [41] developed an EMS for HEV. This approach employed a DRL algorithm that makes use of deep neural networks and Q-Learning to better understand and learn the HEV driving cycles and conditions in order to optimize energy consumption. The tools employed in this study include MATLAB and the advanced vehicle simulator known as ADVISOR from the national renewable energy laboratory (NREL) of the U.S. Department of Energy. Zhang et al. [42] conducted a study involving the use of a fuzzy neural network (FNN) control strategy for the energy 
management of the HEV fuel economy. The FNN approach was based on an optimization algorithm constructed with an adaptive neuro-fuzzy inference. Using the HEV battery SoC as part of the inputs to the FNN, the algorithm was tested using the ADVISOR tool from NREL, and the results indicated an improved fuel economy of $51 \%$.

The capabilities of the future automotive systems technology simulator (FASTSim) application software, which is an advanced vehicle powertrain system analysis and evaluation tool, was exhibited by Brooker et al. [43] as a model that can be used on most types of EVs for the estimation of battery life, efficiency, cost, and performance. A study conducted by $\mathrm{Xu}$ et al. [44] emphasizes the benefit of predicting the energy consumption of large-scale EVs for the purpose of better planning and designing sustainable operations of the EV transportation system. To model the energy consumed by large-scale EVs in this regard, a data-driven model which involves operational parameters from the powertrain was trained using the Bayesian Network. Some of the parameters employed include observable on-road operational parameters including EV speed, acceleration, battery SoC, EV load relating to heating, ventilation, and air conditioning. A system modelling and control application software known as Autonomie was used to generate and evaluate datasets relating to the EV energy consumption profile.

The development of a smart charging system for EV load management is one major aspect that is gaining the attention of industry, academia, and the research community. This is evident in the research and development work conducted by Rajit et al. [45] at the University of California Los Angeles and Lee et al. [46] at the California Institute of Technology. Rajit et al. [45] at UCLA developed an innovative smart EV charging system called WINSmartEV and an infrastructure platform called WinSmartGrid which combines the intelligence of a smart charging algorithm and smart communication network for scheduling large-scale EV distributed charging. The capabilities of the WINSmartEV and the WinSmartGrid also includes remote control and monitoring of large-scale EV charging activities over the network, grid power flow control and monitoring, EV battery SoC, and optimal energy supply management. In the case of Lee et al. [46], an innovative technology known as the adaptive charging network $(\mathrm{ACN})$ was developed to demonstrate how largescale EV can be charged using smart communication devices, protocols, power meters, internet connections, and datasets to control the distributed charging of EVs over the charging network. The significance that open data and models have in the reproducibility of EV research and development which is consistent, scalable, and applicable to any country was emphasized in the study conducted by Yvenn et al. [47]. Further readings on EV load management models and data sources can be found in [47]. Also, data sources on EVs charging profiles and integration can be seen in the review conducted by Calearo et al. [48].

\section{Sustainable Electric Vehicle Charging Infrastructure}

Charging stations are the next big investment in the EV market to sustain the transition from the ICE vehicle to greener EV transportation. Moreover, EV charging stations with renewable energy sources are the most promising solution to reducing carbon emissions and alleviating the significant consequences of EV charging on distribution networks. This section entails literature studies and applications of solar photovoltaic power and battery energy storage system (BESS) as a sustainable energy source for charging EVs.

Developing a sustainable solution for EV charging infrastructure with respect to the renewable energy supply is the key to fully realising the carbon emission-free transportation industry. Unfortunately, technology development has not yet matured to a stage where EVs will completely be off-grid and less dependent on fossil fuel. The techno-economic application of solar power and BESS in the electrification of vehicles is one major aspect that is currently underutilized due to the stochastic and intermittent nature of the power supply. A case study has been provided by Laurischkat et al. [49], where system dynamics was used in Germany to promote the economic and sustainable application of SPP and BESS for charging EVs. Some of the critical parameters considered in this application include the EV driving profile, current electricity price, and household energy requirement. 
Using the Monte Carlo simulation approach to evaluate the economic and energy benefit potentials of solar power and EVs to minimize the cost of electricity in EV to grid (EV2G) and EV to home (EV2H) applications, Lazzeroni et al. [50] employed a similar case study to that mentioned in [49], where solar power is employed in a residential environment for optimal EV battery charging and management. One of the objectives was to reduce the cost of electricity supply from the grid. For this study, the key parameters, including EV battery constraints, driver behaviour in terms of how EVs are being used, household energy requirements, and electricity tariffs, were taken into consideration in other to apply SPP as an alternative clean energy supply.

Wu et al. [51] conducted a study that promotes the application of solar power and BESS integration to household electricity systems in order to efficiently charge EVs. An optimization framework was developed considering solar power, BESS, and plug-in EVs. Using convex programming, this study was able to achieve an optimal BESS capable of supplying the electricity supply requirement of a home during off-peak periods, thereby generating huge financial savings as compared to a home without solar power and BESS. Chowdhury et al. [52] conducted a study that investigated the economic and environmental benefits of SPP application in Bangladesh, India for the purpose of charging EVs.

Minh et al. [53] conducted a study that supports the use of SPP integrated into charging stations to enable large-scale charging of EVs, reduce GHG emissions, and enable a sustainable EV market which is currently lacking in charging infrastructure. This study confirmed that most EVs still depend largely on the fossil fuel-powered electricity distribution network for large-scale EV battery charging. Considering that SPP is stochastic in nature, this study used Vietnam as a case study for the techno-economic analysis and application of SPP integrated to EV charging stations to establish an optimal configuration suitable to meet large-scale EV charging requirements under different solar irradiation atmospheres. Part of the objective was to establish the potential for cities to invest in SPP applications for EV charging based on the level of irradiation available.

Given that EVs takes a long time to get charged due to the large number of battery packs installed, Nishimwe et al. [54] conducted a study that involves the integration of SPP and BESS to develop a fast-charging station for EVs. This study was based on an optimization framework to maximize these combined energy sources to supply EVs with clean energy. Some of the key parameters considered in this study include the intermittent SPP, EV arrival time, scheduling EVs for charging, and the power requirement of the EVs. Part of the objective for this application was to establish a framework for a profitable RES charging station.

For EVs to achieve zero emissions, they should be completely charged off the utility grid, which is majorly coal-dependent. A recent study conducted by Deshmukh et al. [55] investigates the viability of using Walmart, the multinational retail outlet with chains of hypermarkets across the United States, as a case study for the development of Solar Photovoltaic Power (SPP) EV charging stations. In this case, the idea is based on having solar panels as roof covers in large car-parking amenities. The technical detail from this study indicates that about 3.1 MW of SPP can be generated from one retail outlet for charging an estimated $100 \mathrm{EV}$. It was further estimated that the entire chain of Walmart hypermarkets has the potential to provide more than 346,000 SPP EV charging stations and more than $11.1 \mathrm{GW}$ of rooftop SPP generation. The drive towards the 2030 decarbonization of the electricity system in Japan and China has motivated the research conducted by Kobashi et al. [56]. This study investigated the techno-economic assessment of using residential SPP and BESS for charging EVs. The outcome of the study indicated both economic and environmental benefits of using SPP, BESS, and large-scale EV charging and discharging operations to lower the impact of EVs' energy demands from the distribution networks, as well as cutting carbon emissions. It further recommends strategic policies which will encourage the integration of SPP and BESS to household charging stations for EVs. 
The study conducted by Zhao et al. [57] was based on using a different approach to energy management to improve the optimal operation of the distribution network in charging EVs. This approach mainly involves EV charging stations with integrated renewable energy sources comprising SPP and BESS. This study argues that replacing EV batteries with fully charged batteries is more effective towards the optimization of the distribution networks and it allows EV batteries to fully utilize SPP generated while providing an optimal load-shifting strategy. The fragmented energy management approach employed in [57] is such that uses three energy supply sources including the SPP, BESS, and the distribution network to charge EVs at different times and based on the time of use and electricity pricing.

A feasibility study conducted by Ye et al. [58] based on a model of SPP charging stations for large-scale EVs was proposed for the Shenzhen city of China. One of the primary objectives of this study was based on the technical and economic feasibility of developing an SPP charging station that will meet the growing energy demand of EVs' charging requirements. The result from this developed model indicates a combined reduction in GHG emissions of carbon dioxide, sulphur dioxide, and nitrogen oxide with a significant percentage of reduction at $99.8 \%, 99.7 \%$, and $100 \%$, respectively. In analysing the proposed model for SPP EV charging stations and their impacts, Ye et al. [58] conducted a sensitivity analysis using the capital cost of the SPP system, carbon pricing, interest rate, and feed-in tariff policy as parameters for measuring the impacts. The sensitivity analysis for the capital cost of SPP system development shows to have an impact on the Cost of Energy (CoE), in the sense of an increase in the cost of the PV system that including module prices will add to the CoE. The influence of an increase in carbon pricing and raising the emission tax for non-RES will encourage investment and increase the penetration of RES. While an increasing interest rate is a major drawback for investments in RES, policy mechanisms that encourage feed-in tariffs for SPP generation are surely bound to increase investment in RES and a reduction in the global footprint of carbon emissions.

Mazzeo [59] conducted an evaluation on the use of SPP and BESS to set up a residential charging system for EVs. The methodology employed three charging scenarios that involve charging EVs directly from a residential electrical outlet. The second scenario combines SPP, BESS, and grid connection, while the third scenario includes all the power sources in scenario two in the presence of residential load. These energy models or scenarios in one, two, and three were used to determine the significant impact SPP and BESS have on the load satisfaction of EV energy demands when off-grid or grid-connected.

From the literature surveyed in this section, it is important to note the significance of sustainable charging infrastructure for the future of EVs and the battle against the growing global footprint of GHG emissions. Although this study did not investigate the different EV plug configurations and communication protocols that EV manufacturers have built into their vehicles, this study argues that the future of EVs, with regards to its sustainability, also depends on the ability of any EV to have compatible charging connectors to any charging station equipment. Conversely, at best, the EV manufacturers should have a common standard adapter that can be bought off the shelf, this will enable different EVs to convert or adapt their charging ports to any charging station network. The current EV market has made available the charging connectors J1772, CCS, CHAdeMO and Tesla connectors, which are commonly found in the United States and European countries, while the Chinese EV market supports its own proprietary GB/T connector. Figure 4 makes available the visual representation of these EV charger connectors and the typical power ratings [60]. A comprehensive review that provides an extensive information on EV charging methods, including charging standards, levels of charging, and charging configurations was conducted by Arif et al. [61]. This review provides a pathway for countries to adopt methodologies that are based on a feasible framework established for the successful adoption of EVs. 


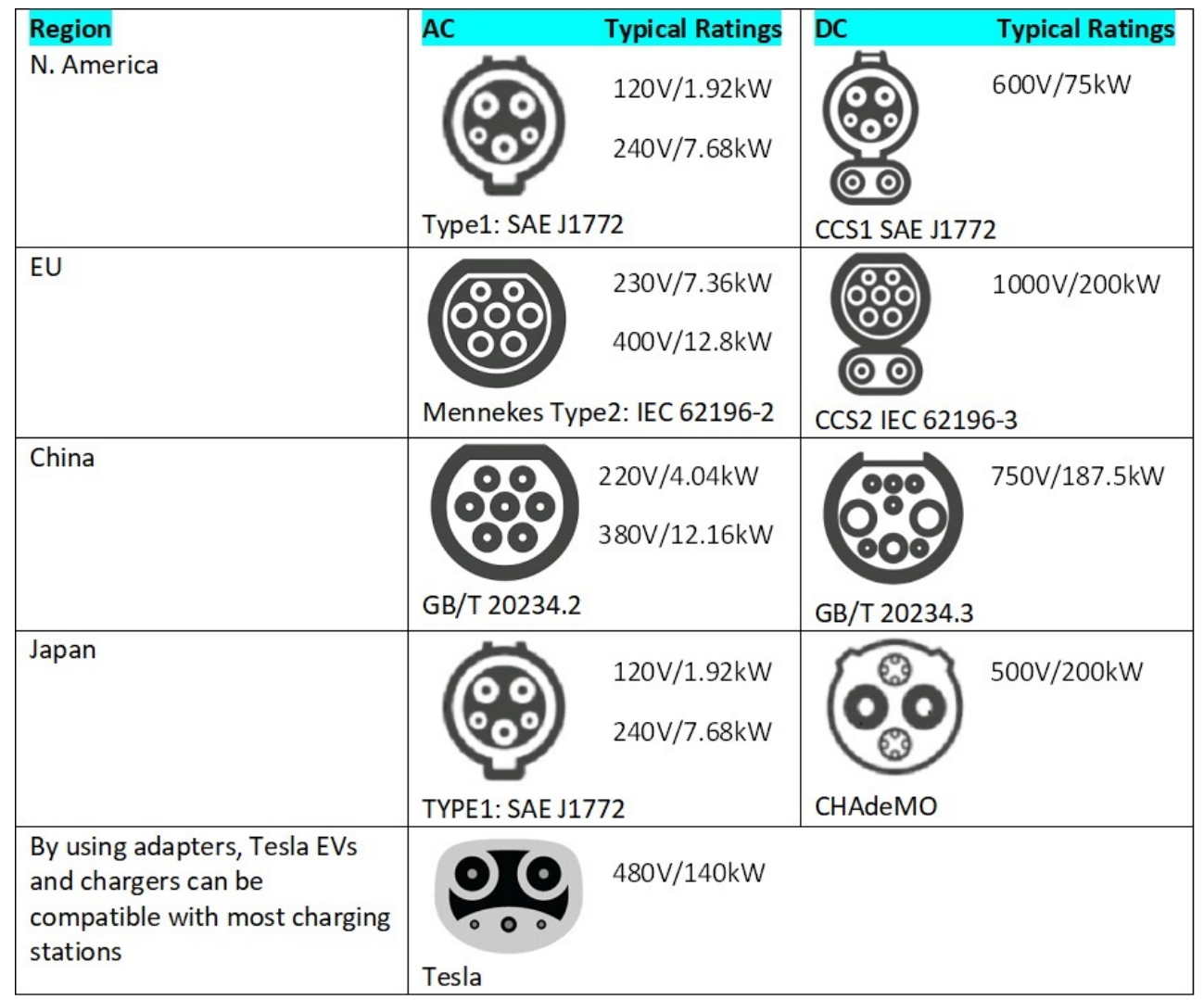

Figure 4. Electric Vehicle Charging Connectors and Configurations [60].

\section{Conclusions and Policy Recommendations to Promote Electric Vehicle Adoption}

This study was mainly an investigation on the future direction of EVs and the sustainability of the transportation sector in relation to EV adoption, whilst also considering the negative impacts of EV energy demands from fossil fuel-powered energy systems and how this undercuts the United Nations Climate Change efforts. Sustainable analysis case studies have been presented on applicable strategies for a global decarbonization roadmap within the transportation industry using EVs and renewable energy sources like the BESS and SPP to power EVs and their charging infrastructure. However, this paper did not investigate the end-of-life (EoL) management of EVs and ICEV components, especially the issues related to the recycling and reuse of batteries and tires, which are composed of chemicals and hydrocarbon materials that may further escalate environmental issues when they are not properly managed. To this end, future research recommendations should look into these issues. The study conducted by Idiano et al., as seen in [62,63], provides a basis for the EoL management of vehicles.

The main issues of this study centre around the future and sustainability of EV transportation in relation to alternative and renewable energy power supplies for EV charging stations that will be off-grid dependent fossil fuel energy, this is in addition to promoting the widespread adoption of EVs in the transportation industry in order to reduce global GHG emissions and fulfilling the initial Paris Agreement (2015) to lower the global average temperature to $1.5^{\circ} \mathrm{C}$.

Although the issue of combating global climate change and reducing the global average temperature to $1.5^{\circ} \mathrm{C}$ may seem to be a herculean task in a global economy that depends heavily on fossil fuel-powered energy systems, this study and review is very significant in providing a future direction for sustainable EV market and the transportation sector which has a direct impact on global climate change. For countries that are seeking to cut their greenhouse gas emissions by one-third, the transportation sector provides a huge opportunity for decarbonization through EV adoption and the implementation of 
RES charging stations for EVs. Furthermore, given the enormous benefits that the EV market provides amidst promoting decarbonization and renewable energy, it offers an opportunity to develop new economies and job creation. Therefore, the government and industry players should create an enabling environment and strategic policies that will support the industrialization of the EV market across economies.

To achieve this, and based on the current EV technology infrastructure deficit in any country vis-à-vis manufacturing capacity to produce EVs and develop the value chain needed to support this market. It is important to consider the renewable energy mix, utility grid capacity for expansion, accessibility of EVs charging stations, business case for government and stakeholders to buy-into the idea of the electrification of the transportation sector, and the return on investments in EVs and climate change benefits. The following recommendations for an EV readiness plan should also be considered in any economy.

i. Tax credits to reduce the high cost and ownership of EVs should be considered as a key factor that will drive EV penetration.

ii. Policies that include carbon tax holidays and financial incentives for businesses that invest in the EV value chain.

iii. Policy to encourage public-private partnerships for the development of EV charging stations that are off-grid, with renewable energy supply sources. This policy can incentivize this initiative through government grant allocation.

iv. Incentives that will encourage and fast-track the development and smooth operation of regional charging equipment and lower the cost of installation for businesses, in public facilities, and at fuel stations.

v. A policy document backed by a government (national, state, municipal, and local government) legislative bill to establish EV charging stations on the streets using existing utility infrastructure such as street light poles to scale the deployment of charging stations and lower the high cost associated with developing entirely new infrastructure. This policy should encourage partnership with governments, utility companies and the private sector to streamline project development in public works, and the required permit processes needed to establish designated charging zones.

vi. A policy that will enable EVs to be parked on the streets in designated EV charging zones that protects EVs from getting traffic tickets and fines.

vii. A policy to incentivize university-industry-based research and development endeavours in public charging infrastructure will further encourage EV adoption.

viii. Economic incentive policy that encourages charging of EVs during off-peak periods, i.e., time-of-use (ToU) electricity pricing.

Author Contributions: R.K. conceived the concept and was responsible for preparing the original draft manuscript; T.O. and B.J.v.W. supervised the development and were responsible for guidance, reviewing, and editing. All authors have read and agreed to the published version of the manuscript.

Funding: This research has been partially supported by the National Research Foundation of South Africa and the Tshwane University of Technology.

Data Availability Statement: Not applicable.

Acknowledgments: The authors would like to appreciate the ongoing support received from the National Research Foundation of South Africa and the Tshwane University of Technology, South Africa.

Conflicts of Interest: The authors declare no conflict of interest.

\section{References}

1. Statista. Largest Oil Consumption Worldwide by Country 2019. Available online: https://www.statista.com/statistics/271622 / countries-with-the-highest-oil-consumption-in-2012/ (accessed on 13 May 2021).

2. U.S. Energy Information Administration. Available online: https://www.eia.gov/energyexplained/us-energy-facts/ (accessed on 13 May 2021).

3. United Nations Climate Change. Available online: https:/ / unfccc.int/sites/default/files/english_paris_agreement.pdf (accessed on 19 May 2021). 
4. Bloomberg New Energy Finance: Electric Vehicle Outlook 2021 Executive Summary. Available online: https:/ /bnef.turtl.co/ story/evo-2021/page/1?teaser=yes (accessed on 23 August 2021).

5. Engel, H.; Hensley, R.; Knupfer, S.; Sahdev, S. Charging Ahead: Electric-Vehicle Infrastructure Demand; McKinsey Center for Future Mobility: Beijing, China, 2018; pp. 1-8. Available online: https://www.mckinsey.com/ \{\}/media/McKinsey/Industries/ Automotive\%20and\%20Assembly/Our\%20Insights/Charging\%20ahead\%20Electric-vehicle\%20infrastructure\%20demand/ Charging-ahead-electric-vehicle-infrastructure-demand-final.pdf (accessed on 23 August 2021).

6. The World Bank. Electric Power Consumption (kWh per Capita)-South Africa 2014. Available online: https://data.worldbank. org/indicator/EG.USE.ELEC.KH.PC?locations=ZA (accessed on 27 July 2021).

7. Khaki, B.; Chung, Y.W.; Chu, C.; Gadh, R. Probabilistic Electric Vehicle Load Management in Distribution Grids. In Proceedings of the IEEE Transportation Electrification Conference and Expo (ITEC), IEEE, Detroit, MI, USA, 19-21 June 2019 ; pp. 1-6.

8. Singh, J.; Tiwari, R. Impact analysis of different charging models for optimal integration of plug-in electric vehicles in distribution system. IET J. Eng. 2019, 2019, 4728-4733. [CrossRef]

9. Hatziargyriou, N.; Karfopoulos, E.L.; Tsatsakis, K. The impact of EV charging on the system demand. In Electric Vehicle Integration into Modern Power Networks; Garcia-Valle, R., Pecas Lopes, J.A., Eds.; Springer: New York, NY, USA, 2013 ; pp. 57-85.

10. Hartmann, N.; Ozdemir, E.D. Impact of different utilization scenarios of electric vehicles on German grid 2030. J. Power Sources 2011, 196, 2311-2318. [CrossRef]

11. Weiller, C. Plug-in hybrid electric vehicle impacts on hourly electricity demand in the United States. Energy Policy 2011, 39, 3766-3778. [CrossRef]

12. Axsen, J.; Kurani, K.S. Anticipating plug-in hybrid vehicle energy impacts in California: Constructing consumer informed recharge profiles. J. Transp. Res. Part D Transp. Environ. 2010, 15, 212-219. [CrossRef]

13. Salah, F.; Ilg, J.P.; Flath, C.M.; Basse, H.; van Dinther, C. Impact of electric vehicles on distribution substations: A Swiss case study. Appl. Energy 2015, 137, 88-96. [CrossRef]

14. Foley, A.; Tyther, B.; Calnan, P.; Gallachóir, Ó. Brian. Impacts of electricity vehicle charging under electricity market operations. Appl. Energy 2013, 101, 93-102. [CrossRef]

15. Fernandes, C.; Frias, P.; Latorre, J.M. Impact of vehicle to grid on power system operation costs: The Spanish case study. Appl. Energy 2012, 96, 194-202. [CrossRef]

16. Habib, S.; Kamran, M.; Rashid, U. Impact analysis of vehicle-to-grid technology and charging strategies of electric vehicles on distribution networks-A Review. J. Power Sources 2015, 277, 205-214. [CrossRef]

17. Reddy, G.H.; Goswami, A.K.; Dev Choudhury, N.B. Impact of plug-in electric vehicles and distributed generation on reliability of distribution systems. J. Eng. Sci. Technol. 2018, 21, 50-59.

18. Dharmakeerthi, C.H.; Mithulananthan, N.; Saha, T.K. Impact of electric vehicle fast charging on power system voltage stability. Int. J. Electr. Power Energy Syst. 2013, 57, 241-249. [CrossRef]

19. Abdalrahman, A.; Zhuang, W. A survey on PEV charging infrastructure: Impact assessment and planning. Energies 2017, 10, 1650. [CrossRef]

20. Jabalameli, N.; Ghosh, A.; Su, X.; Banerjee, B. Stochastic Assessment of Plug-In Electric Vehicles Charging In LV Distribution Network On Voltage Unbalance. In Proceedings of the 9th International Conference on Power and Energy Systems (ICPES), Perth, WA, Australia, 10-12 December 2019; pp. 1-6.

21. Roncancio, I.; Rios, M.A. Spectral and Steady State Impact Assessment of PHEV On Distribution Systems. In Proceedings of the 2013 Workshop on Power Electronics and Power Quality Applications (PEPQA), Bogota, Colombia, 6-7 July 2013 ; pp. 1-6.

22. Wang, L.; Qin, Z.; Slangen, T. Grid impact of electric vehicle fast charging stations: Trends, Standards, Issues and Mitigation Measures-An Overview. IEEE Open J. Power Electron. 2021, 2, 56-74. [CrossRef]

23. Alternative Fuels Data Center, Energy Efficiency and Renewable Energy, U.S. Department of Energy. Available online: https:/ / afdc.energy.gov/vehicles/how-do-all-electric-cars-work (accessed on 24 August 2021).

24. Betancur, D.; Duarte, L.F.; Revollo, J.; Restrepo, C.; Díez, A.E.; Isaac, I.A.; López, G.J.; González, J.W. Methodology to evaluate the impact of electric vehicles on electrical networks using Monte Carlo. Energies 2021, 14, 1300. [CrossRef]

25. Jahangir, H.; Tayarani, H.; Ahmadian, A.; Golkar, M.A.; Miret, J.; Tayarani, M.; Gao, H.O. Charging demand of plug-in electric vehicles: Forecasting travel behavior based on a novel rough artificial neural network approach. J. Clean. Prod. 2019, 229, 1029-1044. [CrossRef]

26. Topic', J.; Skugor, B.; Deur, J. Neural network-based modeling of electric vehicle energy demand and electric range. Energies 2019, 12, 1396. [CrossRef]

27. De Cauwer, C.; Verbeke, W.; Coosemans, T.; Faid, S.; Van Mierlo, J. A data-driven method for energy consumption prediction and energy-efficient routing of electric vehicles in real-world conditions. Energies 2017, 10, 608. [CrossRef]

28. Nageshrao, S.P.; Jacob, J.; Wilkins, S. Charging cost optimization for EV buses using neural network-based energy predictor. IFAC-PapersOnLine 2017, 50, 5947-5952. [CrossRef]

29. Morsalin, S.; Khizir, K.; Town, G. Electric vehicle charge scheduling using an artificial neural network. In Proceedings of the 2016 IEEE Innovative Smart Grid Technologies-Asia (ISGT-Asia), Melbourne, VIC, Australia, 28 November-1 December 2016; pp. 1-5.

30. Jiménez-Bermejo, D.; Fraile-Ardanuy, J.; Castana-Solis, S.; Merino, J.; Alvaro-Hermana, R. Using dynamic neural networks for battery state of charge estimation in electric vehicles. Procedia Comput. Sci. 2018, 130, 533-540. [CrossRef] 
31. Pereira, D.F.; Lopes, F.D.C.; Watanabe, E.H. Nonlinear Model Predictive Control for the Energy Management of Fuel Cell Hybrid Electric Vehicles in Real Time. IEEE Trans. Ind. Electron. 2020, 68, 3213-3223. [CrossRef]

32. Park, S.; Ahn, C. Power management controller for hybrid electric vehicle with predicted future acceleration. IEEE Trans. Veh. Technol. 2019, 68, 10477-10488. [CrossRef]

33. Zhang, S.; Xiong, R.; Sun, F. Model predictive control for power management in a plug-in hybrid electric vehicle with a hybrid energy storage system. Appl. Energy 2017, 185, 1654-1662. [CrossRef]

34. Xiang, C.; Ding, F.; Wang, W.; He, W. Energy management of a dual-mode power-split hybrid electric vehicle based on velocity prediction and nonlinear model predictive control. Appl. Energy 2017, 189, 640-653. [CrossRef]

35. Huang, Y.; Wang, H.; Khajepour, A.; He, H.; Ji, J. Model predictive control power management strategies for HEVs: A review. J. Power Sources 2016, 341, 91-106. [CrossRef]

36. Chen, Z.; Chunting, M.; Xiong, R.; Xu, J.; You, C. Energy management of a power-split plug-in hybrid electric vehicle based on genetic algorithm and quadratic programming. J. Power Sources 2014, 248, 416-426. [CrossRef]

37. Kucevic, D.; Englberger, S.; Sharma, A.; Trivedi, A.; Tepe, B.; Schachler, B.; Hesse, H.; Srinivasan, D.; Jossen, A. Reducing grid peak load through the coordinated control of battery energy storage systems located at electric vehicle charging parks. Appl. Energy 2021, 295, 116936. [CrossRef]

38. Khaki, B.; Chu, C.; Gadh, R. Hierarchical distributed framework for EV charging scheduling using exchange problem. Appl. Energy 2021, 295, 116936. [CrossRef]

39. Li, H.; Wan, Z.; He, H. Constrained EV charging scheduling based on safe deep reinforcement learning. Appl. Energy 2020, $295,116936$. [CrossRef]

40. Novosel, T.; Perkovic, L.; Ban, M.; Keko, H.; Puksec, T.; Krajacic, G.; Duic, N. Agent based modelling and energy planningUtilization of MATSim for transport energy demand modelling. Energy 2015, 92, 466-475. [CrossRef]

41. Hu, Y.; Li, W.; Xu, K.; Zahid, T.; Qin, F.; Li, C. Energy management strategy for a hybrid electric vehicle based on deep reinforcement learning. Appl. Sci. 2017, 8, 187. [CrossRef]

42. Zhang, X.; Liu, Y.; Zhang, J.; Dai, W.; Liu, Z. A fuzzy neural network energy management strategy for parallel hybrid electric vehicle. In Proceedings of the 9th International Conference on Modelling, Identification and Control (ICMIC), Kunming, China, 10-12 July 2017; pp. 342-347.

43. Brooker, A.; Gonder, J.; Wang, L.; Wood, E. FASTSim: A Model to Estimate Vehicle Efficiency, Cost, and performance. In Proceedings of the SAE Technical Paper 2015-01-0973, Detroit, MI, USA, 21-23 April 2015; pp. 1-12. [CrossRef]

44. Xu, X.; Abdul-Aziz, H.M.; Lliu, H.; Rodgers, M.O.; Guensler, R. A scalable energy modeling framework for electric vehicles in regional transportation networks. Appl. Energy 2020, 269, 115095. [CrossRef]

45. Chynoweth, J.; Chung, C.Y.; Qiu, C.; Chu, P.; Gadh, R. Smart Electric Vehicle Charging Infrastructure Overview. In Proceedings of the Innovative Smart Grid Technologies (ISGT), Washington, DC, USA, 19-22 February 2014; pp. 1-5.

46. Zachary, J.L.; Sunash, S.; Steven, H.L. Research Tools for Smart Electric Vehicle Charging. An Introduction to the Adaptive Charging Network Research Portal. In IEEE Electrification Magazine; IEEE: Miami, FL, USA, 2021; Volume 9, pp. 29-36.

47. Yvenn, A.O.; Yannig, G.; Pascal, M.; Jean-Michel, P.; Hui, Y. A review on Electric Vehicle load open data models. Energies 2021, $14,2233$.

48. Calearo, L.; Marinelli, M.; Ziras, C. A review of data sources for electric vehicle integration studies. Renew. Sustain. Energy Rev. 2021, 151, 111518. [CrossRef]

49. Laurischkat, K.; Jandt, D. Techno-economic analysis of sustainable mobility and energy solutions consisting of electric vehicles, photovoltaic systems and battery storages. J. Clean. Prod. 2018, 179, 642-661. [CrossRef]

50. Lazzeroni, P.; Olivero, S.; Repetto, M.; Stirano, F.; Vallet, M. Optimal battery management for vehicle-to-home and vehicle-to-grid operations in a residential case study. Energy 2019, 175, 704-721. [CrossRef]

51. Wu, X.; Hu, X.; Teng, Y.; Qian, S.; Cheng, R. Optimal integration of hybrid solar-battery power source into smart home nanaogrid with plug-in electric vehicle. J. Power Sources 2017, 363, 277-283. [CrossRef]

52. Chowdhury, N.; Hossain, C.A.; Longo, M.; Yaici, W. Optimization of solar energy system for the electric vehicle at University Campus in Dhaka, Bangladesh. Energies 2018, 11, 2433. [CrossRef]

53. Minh, P.V.; Quang, S.L.; Pham, M.H. Technical economic analysis of photovoltaic-powered electric vehicle charging stations under different solar irradiation conditions in Vietnam. Sustainability 2021, 13, 3528. [CrossRef]

54. Nishimwe, L.F.; Yoon, S.G. Combined optimal planning and operation of a fast EV-charging station integrated with solar PV and ESS. Energies 2021, 14, 3152. [CrossRef]

55. Deshmukh, S.S.; Pearce, J.M. Electric vehicle charging potential from retail parking lot solar photovoltaic awnings. Renew. Energy 2021, 169, 608-617. [CrossRef]

56. Kobashi, T.; Say, K.; Wang, J.; Yarime, M.; Wang, D.; Yoshida, T.; Yamagata, Y. Techno-economic assessment of photovoltaics plus electric vehicles towards household-sector decarbonization in Kyoto and Shenzhen by year 2030. J. Clean. Prod. 2020, $253,119933$. [CrossRef]

57. Zhao, Z.; Wang, K.; Li, G.; Jiang, X.; Wang, X. Economic dispatch of distribution network with in for electric vehicles and photovoltaic. J. Eng. 2019, 2019, 2864-2868. [CrossRef]

58. Ye, B.; Jiang, J.; Miao, L.; Yang, P.; Li, J.; Shen, B. Feasibility study of a solar-powered electric vehicle charging station model. Energies 2015, 8, 13265-13283. [CrossRef] 
59. Mazzeo, D. Nocturnal electric vehicle charging interacting with a residential photovoltaic-battery system: A 3E (energy, economic and environmental) analysis. Energy 2019, 168, 310-331. [CrossRef]

60. Khaligh, A.; D'Antonio, M. Global trends in high-power on-board chargers for electric vehicles. IEEE Trans. Veh. Technol. 2019, 68, 3306-3324. [CrossRef]

61. Arif, S.M.; Lie, T.T.; Seet, B.C.; Ayyadi, S.; Jensen, K. Review of electric vehicle technologies, charging methods, standards and optimization techniques. Electronics 2021, 10, 1910. [CrossRef]

62. D'Adamo, I.; Rosa, P. A structured literature review on obsolete electric vehicles management practices. Sustainability 2019, 11, 6876. [CrossRef]

63. D'Adamo, I.; Gastaldi, M.; Rosa, P. Recycling of end-of-life vehicles: Assessing trends and performances in Europe. Technol. Forecast. Soc. Chang. 2019, 152, 119887. [CrossRef] 